\title{
Social media adoption in the police: Barriers and strategies ${ }^{\text {is }}$
}

\author{
Rianne Dekker ${ }^{\mathrm{a}}$, Puck van den Brink ${ }^{\mathrm{b}}$, Albert Meijer ${ }^{\mathrm{a}, *}$ \\ ${ }^{a}$ Utrecht University, Bijlhouwerstraat 6, 3511 ZC Utrecht, The Netherlands \\ ${ }^{\mathrm{b}}$ TNO, Lange Kleiweg 137, 2288 GJ Rijswijk, The Netherlands
}

A R T I C L E I N F O

\section{Keywords:}

Social media

Social media policy

Adoption barriers

Innovation

Police

\begin{abstract}
A B S T R A C T
Public organizations often face numerous barriers when it comes to adopting and using social media to communicate and engage with the broader public. This research aims to better understand how barriers to social media adoption can be tackled by zooming in on one specific type of organization: the police. Our research answers the following question: to what effect do police forces manage barriers to the adoption of social media with social media policies? Firstly, by systematically reviewing previous studies using a typology of barriers to ICT adoption, this study identifies the types of barriers that the police are often faced with. Secondly, by qualitatively analyzing two frontrunner cases, the United Kingdom and the Netherlands, this study analyzes how social media policies address and can help overcome these barriers. The empirical analysis indicates that in addressing barriers to social media adoption, a combination of exploration and exploitation is needed to address both structural and cultural barriers to social media adoption. We argue that this fits an approach of the 'perpetual beta': ongoing technological innovation requires organization capacity to continuously adapt to sociotechnical change.
\end{abstract}

\section{Introduction}

Social media enable many-to-many exchanges of user-generated content which can benefit public organizations (Bertot et al., 2012; Picazo-Vela et al., 2012). For the police, social media not only offer new opportunities for operational tasks, such as criminal investigation, intelligence and crowd control, but also for communicative tasks of engaging and interacting with the general public (Crump, 2011; Manzoor, 2015; Meijer and Thaens, 2013; Meijer and Torenvlied, 2016; Schneider, 2016). The police can use social media platforms such as Twitter and Facebook to warn citizens about threats, encourage citizens to report problems and engage citizens in investigations. There seem to be many reasons why the police should be adopting social media to improve communication with citizens.

Despite these potential opportunities, the police have only cautiously adopted social media (Crump, 2011; Medi@4Sec, 2016). As hierarchical organizations, the police often use social media for one-tomany broadcasting rather than many-to-many dialogue (cf. Brainard, 2016; Zavattaro and Brainard, 2019). This suggests that police forces have not realized the full potential of social media and that barriers to social media adoption exist. This mirrors a broader pattern of public organizations that are hesitant to fully integrate social media into their organizational processes (Mergel, 2013; Mergel and Bretschneider, 2013; Oliveira and Welch, 2013; Picazo-Vela et al., 2016).

This study focuses on the police to contribute to a broader understanding of how public organizations can manage barriers to social media adoption with policies. The following research question guides this analysis: to what effect do police forces manage barriers to the adoption of social media with social media policies? To gain a comprehensive understanding of the way in which policies help overcome barriers to social media adoption, this study consists of two analyses which will be presented subsequently. First, a systematic review of evidence in literature to identify the common barriers the police are faced with. This review is guided by the sub-question: What are the main types of barriers to social media adoption facing the police? We conduct a meta-synthesis of structural and cultural barriers on the part of government and citizens (Meijer, 2015).

The meta-synthesis subsequently informs the in-depth policy analysis of how two European frontrunner cases address these barriers and addresses the sub-question: What policies have frontrunner police forces implemented to overcome these barriers? Police in the Netherlands and the UK are considered frontrunners in social media adoption in the European Union, considering their numbers of social media accounts and as indicated by a review of European best practices through expert

\footnotetext{
The research reported in this paper was funded by the European Union's Horizon 2020 Research and Innovation Program, under Grant Agreement no 700281.

* Corresponding author.

E-mail addresses: r.dekker1@uu.nl (R. Dekker), puck.vandenbrink@tno.nl (P. van den Brink), a.j.meijer@uu.nl (A. Meijer).
} 
opinions (Medi@4Sec, 2016). Policies of Dutch and UK police forces are analyzed through the twin concepts of exploration and exploitation pointing at developing new practices and improving existing practices (Gupta et al., 2006; March, 1991).

The analysis demonstrates that cultural barriers on the side of government are most diverse and challenging to police. Police forces that are frontrunners in the adoption of social media overcome barriers by combining strategies of exploration and exploitation of social media technologies: their policies leave room for differentiated practices and experimentation within set processes and boundaries.

\section{Adoption of social media in the public sector}

\subsection{Barriers to social media adoption in the public sector}

Literature on social media adoption in the public sector stresses that adoption of social media changes internal processes of public organizations and the ways in which they interact with the public externally (Criado et al., 2013). Integration of social media into organizational processes, however, brings various challenges. Public organizations face problems of introducing, embedding and sustaining the use of these technologies within their institutional structure and organizational culture (Mergel, 2012; Campbell et al., 2014; Dekker and Bekkers, 2015).

In this process of adopting innovative practices, public organizations can encounter several types of barriers. Earlier studies of social media adoption by public organizations tend to emphasize structural barriers on the side of government (Mergel, 2012; Picazo-Vela et al., 2016). These are barriers that that stop or slow down innovation and can be overcome by organizational actors (Meijer, 2015). For example, Moon (2002) highlights barriers such as personnel capacity, technical capacity (number of information technology (IT) staff and IT skills), financial capacity and legal issues. Eynon and Margetts (2007) call our attention to the availability of hardware and software and interoperability.

To provide a more generic perspective on barriers to technological innovation in the public sector, Meijer (2015) builds upon studies such as Margetts and Dunleavy (2002), Eynon and Dutton (2007) and Eynon and Margetts (2007) to broaden this analysis. This model adds cultural barriers of organizational or individual values that work against the development of electronic services (Margetts and Dunleavy, 2002: 5; Meijer, 2015: 199). Furthermore, it emphasizes that technologies do not only need to be accepted by government organizations - in the case of our research: the police - but also by citizens (Margetts and Dunleavy, 2002). We use these two dimensions to analyze four types of barriers to social media adoption in the public sector (see Table 1).

\subsection{Strategies for tackling barriers to innovation: exploration and exploitation}

To develop a framework for analyzing how the police can tackle these barriers, we build not only on the literature on social media in the public sector but also upon the broader literature on innovation strategies. Much of the literature on innovation stresses that realizing innovation requires strategic action that consists of both experimenting with new ideas and embedding these in organizational practices (Bloch and Bugge, 2013; Dodgson et al., 2008). From a more generic perspective on organizational action, March (1991: 205) stated that 'adaptation requires both exploitation and exploration to achieve persistent success'. Exploration deals with discovering new possibilities by way of variation, experimentation and play (Gupta et al., 2006; March, 1991). Exploitation refers to capitalizing on certainties through the use of existing knowledge and replication of actions, broader application and improvement of routines. In evolutionary terms: selection and retention of proven practices.

Adoption of innovation in general and social media in particular in public organizations is often described as a staged process moving from exploration to exploitation (Coursey and Norris, 2008; Mergel and Bretschneider, 2013; Osborne and Brown, 2005; Rogers, 2003). In the first stage, social media are adopted informally by individual change agents who diffuse the technology locally within their organizations. Through experimentation, applications and usage will expand. However, the first barriers may emerge. Public organizations may, for example, experience that social norms for using social media do not fit their professional work environments. In the second stage, informal standards emerge in response to problems and inappropriate uses. These standards still leave enough flexibility for different practices and subunits within the organization to use social media differently (Mergel and Bretschneider, 2013). These two stages fit a strategy of 'exploration' of new possibilities.

In the third and final stage, organizations approach the adoption of social media via 'exploitation'. Guidelines for the use of social media in the organization are formulated. This stage is characterized by establishing an official social media policy to guide the desired ways of using social media. It may also prescribe norms for citizens interacting with government through government social media channels (Mergel and Bretschneider, 2013: 395). Online etiquette or 'netiquette' are prescribed to ensure appropriate language and on-topic comments. In this final stage of social media adoption, formal policies encourage the use of the technology, create uniformity in use and prevent organizational failure associated with the technology (Mergel and Bretschneider, 2013: 397; Picazo-Vela et al., 2016).

This overview of the general literature on organizational innovation and the literature on social media adoption in the public sector highlights that policies on social media adoption outline measures that are taken to address barriers to social media adoption. The character of these measures and choices in whether actions are regulated or not, are indicative of exploitation and exploration strategies to innovation. Staged models suggest that exploration and exploitation follow a sequential logic. However, findings from studies of innovation note that the adoption of innovation is best represented as an iterative process, and not a linear one. This study analyzes whether a strategy of exploration or exploitation prevails in two police cases of advanced practices of social media adoption.

\section{Methodology}

The aim of this paper is to analyze how police tackle barriers to social media adoption through the development of specific policies. However, policies usually present solutions without extensively discussing the problems that they address. To gain a comprehensive understanding of the way in which policies overcome barriers to social

Table 1

Typology of barriers to e-governance innovation (Meijer, 2015: 200).

\begin{tabular}{|c|c|c|}
\hline & Government & Citizens \\
\hline Structural & $\begin{array}{l}\text { Legal constraints, lack of finances, shortage of personnel and available skills, limited } \\
\text { political and management support, lack of coordination, technological constraints }\end{array}$ & $\begin{array}{l}\text { Lack of technological facilities, limited knowledge and competences, } \\
\text { shortage of time, failure to integrate innovation in daily routines }\end{array}$ \\
\hline Cultural & $\begin{array}{l}\text { Resistance to change, fear that innovation undermines the robustness of government, } \\
\text { interference with bureaucratic culture }\end{array}$ & $\begin{array}{l}\text { Lack of interest, little faith in and negative image of government, no } \\
\text { perceived usefulness, resistance to technology }\end{array}$ \\
\hline
\end{tabular}


media adoption by police, we combine in-depth policy analysis of two advanced cases with a systematic literature review. A systematic review of earlier studies of social media use by police forces enables us to identify common types of barriers. The in-depth analysis of social media policies of two police forces that have effectively adopted social media enables us to identify which barriers are addressed and which innovation approach prevails.

\subsection{Systematic literature review to identify barriers}

A systematic literature review is defined as a 'systematic, explicit, and reproducible method for identifying, evaluating, and synthesizing the existing body of completed and recorded work produced by researchers, scholars and practitioners' (Fink, 2010: 3). We use the 'Preferred Reporting Items for Systematic reviews and Meta-Analyses' (PRISMA) statement as a method to ensure transparent and complete reporting of the review (Liberati et al., 2009; Moher et al., 2009). We conducted a qualitative meta-synthesis (Walsh and Downe, 2005; Zimmer, 2006) of the set of publications in order to answer our research questions. This entails comparative analysis of the contents of the publications in light of the research question from which new interpretations of the findings are generated.

We identified relevant records in two of the largest academic databases that cover a large set of social science journals: Scopus and Web of Knowledge - Social Science Citation Index (WoK-SSCI). We used a search string combining search terms related to policing and social media to find publications on the nexus of these topics: ("police" OR "policing" OR "law enforcement" OR "LEA ${ }^{1 "}$ OR "LEAs" OR "public security" OR "public safety" OR "crim*") AND ("social media" OR "Facebook" OR "Twitter" OR "web 2.0" OR "web 3.0" OR "user?generated content" OR "new media" OR "social network* site*" OR "blog*" OR "weblog*" OR "online discussion for*" OR "app" OR "apps" OR "smart?phone*" OR "website"). Four search parameters were applied: a) the search string should appear in the publication title; b) the query was limited to the domain of social science; c) we only included publications written in English; and d) we only included academic journal articles, books and book chapters to ensure rigor and avoid including corresponding reports or conference papers.

The search on July 26, 2018 yielded 96 results in Scopus and 56 in Web of Knowledge. The combined list of 152 records included 40 duplicates which were removed. Five publications were not accessible through our university library. We contacted the authors via email to request a full text version of the publications. This way, we retrieved three publications (Jones et al., 2014; Jones and De Guzman, 2010; Manzoor, 2015). Two publications needed to be excluded due to lack of access. The eligibility of publications for this study was assessed in two subsequent rounds of checking publication titles and abstracts. 69 records were removed from the list because of one of several reasons: (1) publications focusing on social media uptake for police tasks beyond communication and engagement (such as the use of social media data in police investigations); (2) publications addressing 'policing' behavior of citizens on social media; (3) publications addressing the relationship between social media use by citizens and fear of crime; and (4) publications addressing attitudes towards law enforcement that are voiced on social media. We included a total of 41 publications in our analysis (Fig. 1).

After retrieving full-text versions of all publications, we used Meijer's (2015) typology as a framework to analyze barriers to social media adoption. Relevant excerpts on expected and experienced barriers in the adoption of social media in policing were coded. The coding for structural barriers consisted of perceived difficulties with working with social media and organizational obstacles that slow down or put innovation concerning social media on hold. The coding for cultural

\footnotetext{
${ }^{1}$ Abbreviation of 'law enforcement agency'
}

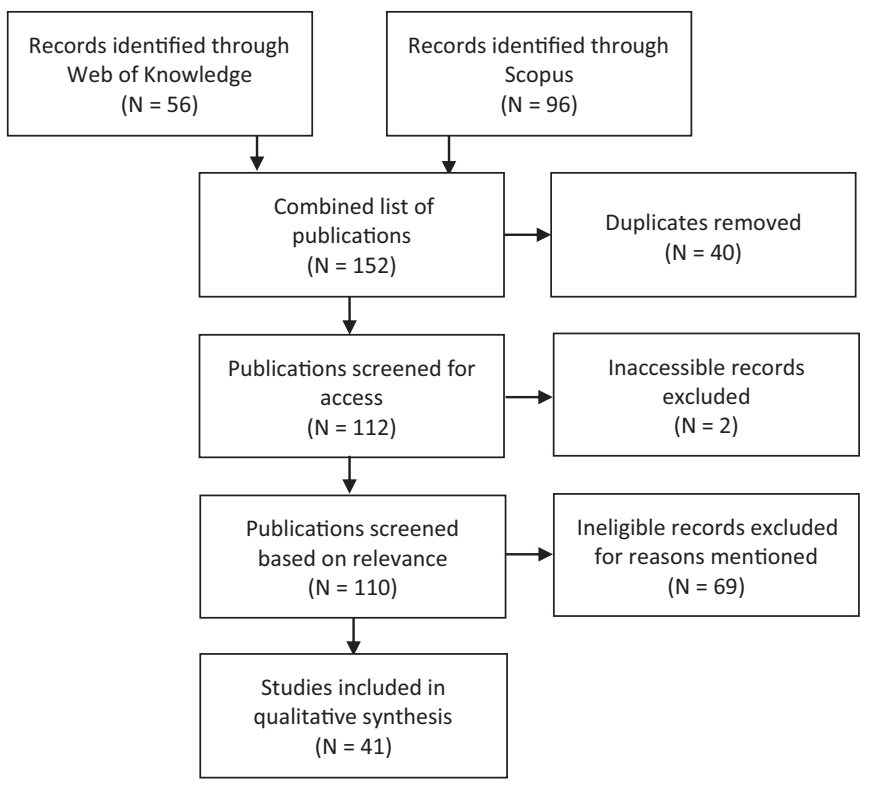

Fig. 1. PRISMA flow diagram

barriers consisted of perceived organizational or individual values that work against innovation or could be put at risk by social media. For example, social media communication posing risks to police reputation was coded as a cultural barrier on the side of government. This indicates a fear that social media may undermine bureaucratic culture (cf. Table 1). We exported these text fragments to an Excel spreadsheet listing all publications. In the second round of coding the exported text fragments, we clustered similar findings of various publications and meta-synthesized their meaning in terms of the typology of barriers. To increase the reliability of the analysis, six publications were independently coded by two of the researchers and inter-coder differences were extensively discussed to strengthen the coding rules.

\subsection{Qualitative case study to analyze policies for tackling barriers}

The second part of the analysis entailed qualitative analysis of social media strategies of police organizations in two countries that are considered frontrunners in their adoption of social media: the United Kingdom and the Netherlands. This is indicated by their numbers of social media accounts and a review of European best practices through expert opinions (Medi@4Sec, 2016). The Dutch police has over 2300 accounts on Facebook, YouTube, Instagram and Twitter (Dutch police, 2018). Police forces in the UK have nearly 2500 accounts which comprise 48 corporate and 2450 decentralized accounts (Fernandez et al., 2017). These two advanced cases can teach us how barriers in social media adoption can be effectively managed and overcome.

Policies of these police forces provide a good overview of which strategies are taken to foster innovation. Relevant policy documents were retrieved through public police websites, personal contacts with social media managers within the police forces and freedom of information requests. The Dutch police is organized as one national police force and has published a national social media policy document with two appendices on the use of images on social media. Law enforcement in the United Kingdom is organized in 45 territorial police forces within three police jurisdictions: England and Wales (43 constabularies), Northern-Ireland (1 constabulary), and Scotland (1 constabulary). In addition to the social media policies of the Police Service of Scotland and the Police Service of Northern Ireland (PSNI), we included the social media policy of the Metropolitan Police Service (MPS) as the largest constabulary within the jurisdiction of England and Wales. These three territorial police forces not only cover all three police 
Table 2

Analyzed social media policy documents of UK and Dutch police.

\begin{tabular}{|c|c|}
\hline UK police & Dutch police \\
\hline $\begin{array}{l}\text { - Association of Chief Police Officers/National Police Chiefs' Council (2011). Engage: } \\
\text { Digital and Social Media Engagement for the Police Service. Retrieved December 6, } \\
2019 \text { from: http://connectedcops.net/wp-content/uploads/2010/04/engage.pdf } \\
\text { - Association of Chief Police Officers/National Police Chiefs' Council (2013). Guidelines } \\
\text { on the Safe use of the Internet and Social Media by Police Officers and Police Staff. } \\
\text { Retrieved December 6, } 2019 \text { from: https://assets.publishing.service.gov.uk/ } \\
\text { government/uploads/system/uploads/attachment_data/file/329509/Guidelines- } \\
\text { socialmedia-v1-jan13.pdf }\end{array}$ & $\begin{array}{l}\text { - Dutch police (2018). Social media regulations. (Version 1.1). Department of } \\
\text { Digitalization and Cybercrime, Directorate of Communication. Retrieved December 6, } \\
2019 \text { from: https://www.politie.nl/binaries/content/assets/politie/algemeen/ } \\
\text { onderwerpteksten/social-media/20180905-platformonafhankelijke-social-media- } \\
\text { afspraken_2017_v1-1.pdf } \\
\text { - Dutch police (2018a). Instruction images on social media. Retrieved December 6, } 2019 \\
\text { from https://www.politie.nl/binaries/content/assets/politie/algemeen/ } \\
\text { onderwerpteksten/social-media/instructie-beeld-op-social-media.pdf }\end{array}$ \\
\hline \multicolumn{2}{|l|}{$\begin{array}{l}\text { - College of Policing (2017). Authorized professional practice 'Engagement and } \\
\text { communication'. Retrieved October 10, } 2018 \text { from: https://www.app.college. } \\
\text { police.uk/app-content/engagement-and-communication/ }\end{array}$} \\
\hline $\begin{array}{l}\text { - Metropolitan Police (2017). One Met: Digital Policing Strategy 2017-2020. London: } \\
\text { Metropolitan Police.Retrieved December 6, } 2019 \text { from: https://www.met.police. } \\
\text { uk/SysSiteAssets/media/downloads/met/about-us/one-met-digital-policing- } \\
\text { strategy-2017-2020.pdf }\end{array}$ & $\begin{array}{l}\text { - Dutch police (2018b). Infographic images on social media. Retrieved December 6, } 2019 \\
\text { from https://www.politie.nl/binaries/content/assets/politie/algemeen/ } \\
\text { onderwerpteksten/social-media/infographic-beeld-op-social-media.pdf }\end{array}$ \\
\hline \multicolumn{2}{|l|}{$\begin{array}{l}\text { - Metropolitan Police (2017). MPS Media Policy. Directorate of Media and } \\
\text { Communication. Retrieved December 6, } 2019 \text { from: https://www.met.police.uk/ } \\
\text { SysSiteAssets/foi-media/metropolitan-police/policies/met-hq—portfolio- } \\
\text { planning_mps-media-policy }\end{array}$} \\
\hline \multicolumn{2}{|l|}{$\begin{array}{l}\text { - Police Scotland (2018). Media Standard Operating Procedure. Corporate } \\
\text { Communications. Retrieved December 6, } 2019 \text { from: https://www.scotland. } \\
\text { police.uk/assets/pdf/151934/184779/media-sop }\end{array}$} \\
\hline \multicolumn{2}{|l|}{$\begin{array}{l}\text { - Police Scotland (2016). Social media. Presentation by Corporate Communications. } \\
\text { Retrieved December 6, } 2019 \text { from: https://www.cdn.ac.uk/wp-content/uploads/ } \\
\text { 2016/05/Part-1-PoliceScotland-social-media.pdf }\end{array}$} \\
\hline $\begin{array}{l}\text { - Police Service of Northern Ireland (2017). Social Media. Service Instruction } 2017 . \\
\text { Retrieved December 6, } 2019 \text { from: https://www.psni.police.uk/globalassets/ } \\
\text { advice-information/our-publications/policies-and-service-procedures/social- } \\
\text { media-230217.pdf }\end{array}$ & \\
\hline
\end{tabular}

jurisdictions, they also constitute the largest UK police forces in terms of budget and numbers of police officers. We expect that social media policies of other UK police forces will be relatively similar. In addition, we analyzed the social media guidelines of the National Police Chiefs' Council (NPCC - formerly known as the Association of Chief Police Officers, ACPO). This organization led the development of a national policy agenda to engage citizens in local policing through social media (Crump, 2011). Their guidelines inform the social media policies of local police forces in England, Wales and Northern Ireland and the authorized professional practice on engagement and communication of the College of Policing. The list of 11 policy documents included in our analysis is presented in Table 2.

The analysis of police social media policies focused on how barriers to social media adoption are addressed. In each policy document, we coded specific measures and guidelines. In a second round of coding we matched these measures with barriers to social media use that they are meant to address. Sometimes barriers were described explicitly, in other cases they were implied. For example, 'ten golden rules' prescribing norms of police communication on social media, could be matched with the cultural barrier of damage to police reputation. We exported excerpts of the policies to an Excel spreadsheet listing all barriers that emerged through the literature review. This allowed us to qualitatively analyze which barriers identified in our literature review the policies were designed to address.

Furthermore, we analyzed the broader social media adoption approaches to evaluate the type of innovation strategy employed. Variation, experimentation and play were considered indicative of an explorative innovation strategy. Replication, broader application and improvement of existing routines were considered as signs of exploitation (Gupta et al., 2006; March, 1991). Thus, policies experimenting with new practices were coded as exploration and policies aimed at embedding social media in existing practices were coded as exploitation. This enabled us to review what type of innovation strategy led to overcoming barriers. All policy documents were coded by two researchers, and the coding was extensively discussed to improve coding rules and inter-coder agreement.

\section{Barriers to social media adoption by police forces}

This section discusses barriers identified in academic studies of social media adoption by police departments. The types of barriers considered include: structural government barriers, cultural government barriers, structural citizen barriers and cultural citizen barriers. Each barrier will be discussed in turn.

\subsection{Structural government barriers}

Several structural barriers exist on the side of police organizations. Firstly, resources are required for social media adoption. While it is relatively easy and cheap to start a personal account on social media, implementing and maintaining a professional web-presence requires a significant amount of resources, including investments in hardware and software (Jones and De Guzman, 2010). Furthermore, social media presence raises expectations of quick responses to citizen requests and frequent interaction with the local community (Fowler, 2017; Omanga, 2015). Time and personnel need to be reserved to manage such an active social media presence (Edlins and Brainard, 2016; Heverin and Zach, 2010).

Secondly, structural government barriers relate to efforts of embedding social media in existing organizational processes (Ho et al., 2014). Police forces differ in managing social media communications centrally or personally. When social media communication is centralized, networking within the organization is required to distribute timely and relevant information (Williams et al., 2018). When social media communication is decentralized, the consistency, professionalism and security of accounts needs to be managed (Heverin and Zach, 2010; Sillince and Brown, 2009; Yavuz and Welch, 2014).

Finally, structural government barriers relate to the management of social media communication. Studies identify a lack of clear protocols for working with social media (Meijer and Torenvlied, 2016). There is a need for guidance in how often police should post, on what platforms they should be present and whether they should respond to all citizens requests, including trolling (Williams et al., 2018; O'Connor, 2017; 
Beshears, 2017). Furthermore, it is not clear whether and how police should respond to criminalized communicative acts such as death threats and hate speech on social media (Trottier and Fuchs, 2014). Some police officers experience social media activities as acting in a grey area and would feel safer using social media if regulations were provided (Bullock, 2018b).

\subsection{Cultural government barriers}

Studies also identified several cultural barriers on the side of government. Firstly, some studies argue that social media culture is incompatible with the culture of the police organization. Social media require an open and personal communication strategy which typically includes relatable and authentic content, as well as a degree of humor (Bullock, 2018a; Davis et al., 2015; Manzoor, 2015; O'Connor, 2017; Schneider, 2016). This conflicts with police forces which operate from an authoritative mode of law enforcement (Bullock, 2018b; De Graaf and Meijer, 2019), particularly when there is a police subculture of distrust in citizens (Edlins and Brainard, 2016).

Secondly, there are several cultural challenges which limit the effective use of social media. Social media come and go and evolve in popularity and type of audiences. It is difficult for police forces to adapt their style of communication to different platforms in a way that allows them to have a meaningful presence (Dai et al., 2017; Procter et al., 2013). Some studies identify a tension between the maintenance of multiple social media accounts and delivering consistent communication (Madichie and Hinson, 2014). Others argue that police presence on different social media platforms should be adjusted to the different target groups in order to communicate effectively (Dai et al., 2017; Sillince and Brown, 2009; Huang et al., 2017) and also be adaptable to features of each social media platform (Procter et al., 2013; Van De Velde et al., 2015).

Finally, there are several risks to police reputation due to the heightened visibility of policework through social media. Police do not have full control over their public image and can have their legitimate authority challenged via social media (Bohanon, 2016; Schneider, 2014; Toch, 2012; Greer \& McLaughlin, 2010; Earl et al., 2013). For example, public relation efforts may backfire or be inadequate, and confusing or improper content can damage police reputation and trust of citizens in the police (De Graaf and Meijer, 2019; Edlins and Brainard, 2016; O'Connor, 2017). Examples of expressions of extreme, prejudiced or political views and undesirable associations on police social media accounts are extensively discussed in previous studies (Edlins and Brainard, 2016; Goldsmith, 2015).

\subsection{Structural citizen barriers}

In addition to structural barriers present within the police, several structural barriers also exist on the part of citizens. Firstly, there are digital inequalities in society: citizens of higher age, lower education, minority groups and rural communities generally have less access to and acquaintance with social media (Lieberman et al., 2013; Rosenbaum et al., 2011; Ruddell and Jones, 2013). This means that police communication on social media reaches only a select segment of the public (Grimmelikhuijsen and Meijer, 2015; Williams et al., 2018). Communication on social media should therefore not replace other forms of police communication.

Secondly, the relative anonymity of social media communities and cultivated habits of expression with irony and sarcasm creates ambiguity and confusion by removing the context needed for police to interpret messages (Manzoor, 2015; Meijer and Thaens, 2013). Dealing with informal, unstructured information of citizens may lead to misinterpretation of misleading information or trolling. However, ignoring messages when a response is required, leads to frustrations and disappointment among citizens which will negatively affect further interactivity and engagement (Jones and De Guzman, 2010).

\subsection{Cultural citizen barriers}

Studies also identify cultural barriers on the side of citizens. Firstly, several studies signal a mismatch between police and citizen perceptions of how to interact on specific social media platforms and how to distinguish authentic police presence. There is a proliferation of fake police accounts that spread rumors and speculations (Manzoor, 2015). Citizens sometimes confuse these bogus accounts with real police accounts.

Secondly, cultural barriers relate to trust of citizens in the police and their willingness to engage. A study in Kenya, for example, shows that citizens who view the police as an extension of a repressive state are less willing to engage with police on social media (Omanga, 2015). Instead of a service or partnership, social media presence may then be experienced as a form of surveillance in a space that citizens have claimed as their own (Schneider, 2016; Trottier and Fuchs, 2014). Other studies encountered a lack of interest rather than a lack of trust: citizens simply may not wish to or have time to follow police accounts and engage with policework though social media (Brainard and Edlins, 2015).

Finally, active police communication on social media may have perverse effects of inciting fear of crime by creating increased visibility of crime and disorder (Lieberman et al., 2013). One study suggested that police departments can minimize crime-related posts and instead emphasize messages that focus on other police-related activities ( $\mathrm{Hu}$ et al., 2018). Relatable posts on daily work, pictures of animals, acts of kindness and witty comments on current events result in more response and engagement (Bullock, 2018a; Williams et al., 2018).

\subsection{Analysis of main barriers to social media adoption}

Table 3 presents an overview of the barriers to social media adoption. We identified barriers within all four categories, but the studies primarily discussed structural and cultural barriers on the side of

Table 3

Barriers to adoption of social media by police

\begin{tabular}{|c|c|c|}
\hline & Government & Citizens \\
\hline Structural & $\begin{array}{l}\text { - Limited resources (hardware, software and personnel, including lack of managerial } \\
\text { commitment); } \\
\text { - No embedding of social media in existing organizational processes leading to lack of } \\
\text { training and knowledge exchange; } \\
\text { - No management of social media communication: lack of clear protocols and guidance. }\end{array}$ & $\begin{array}{l}\text { - Digital inequalities and unequal reach of communication because } \\
\text { certain groups are less acquainted with social media; } \\
\text { - Relatively anonymous, unstructured and informal social media requests } \\
\text { may be misinterpreted. }\end{array}$ \\
\hline Cultural & $\begin{array}{l}\text { - Lack of fit of social media culture with police culture of communication (horizontal, } \\
\text { informal and many-to-many vs. hierarchical, formal and one-to-many); } \\
\text { - Ineffective communication on social media due to challenges related to the adaptability } \\
\text { to the (changing) social media landscape, fitting communication to each platform's target } \\
\text { group and features; } \\
\text { - Risks to police reputation and legitimacy due to heightened visibility of policework on } \\
\text { social media. }\end{array}$ & $\begin{array}{l}\text { - Mismatch of social media in style of communication; citizens mistaking } \\
\text { bogus police accounts for real; } \\
\text { - Limited trust of citizens in the police causing limited willingness to } \\
\text { engage since social media presence may be regarded as surveillance; } \\
\text { - Perverse effects of enhanced fear of crime due to more frequent } \\
\text { communication on crime. }\end{array}$ \\
\hline
\end{tabular}


government. The fact that cultural government barriers were strongly present adds to current theory on social media adoption which mostly stresses the structural barriers on the side of government organizations (Mergel, 2012; Picazo-Vela et al., 2016).

\section{Strategies to overcome barriers to use social media}

Analysis of the policies of two advanced cases - police in the UK and the Netherlands - helps to understand how barriers to social media adoption can be effectively managed.

\subsection{Overcoming structural government barriers}

The policies included in this study convey a message of managerial support for social media use. In general, this support provides a strong basis for obtaining resources. Some policies mention that the organization will provide a platform for monitoring social media or digital devices to use social media (Metropolitan Police, 2017; PSNI, 2017). PSNI (2017:7) for example provides training for police officers to effectively monitor and answer social media requests through a social media management dashboard. The Dutch policy (2018: 7) states that agreements on time, capacity and resources to use social media need to be made with the team chief.

There are multiple strategies which are used to embed social media into existing processes. Most social media policies specify or divide responsibilities in social media communication (PSNI, 2017; Dutch police, 2018). For example, the Metropolitan police and Police Scotland both specify as a rule of thumb for individual police officers to ask themselves: 'am I the person responsible for communicating about this issue and is there a policing purpose for doing so?' Starting a social media account usually requires formal application with upper management (PSNI, 2017). Social media policies also specify rules for ensuring security and legal compliance of the accounts by regularly changing passwords and adjusting privacy settings (Dutch police, 2018; PSNI, 2017; College of Policing, 2017; ACPO, 2011; 2013). Policies provide guidelines to ensure uniformity and consistency of use by referring to a style guide (PSNI, 2017; Dutch police, 2018).

Disclosure of confidential information and unauthorized disclosure of personal data are identified as important risks to police communication (ACPO, 2013: 5). Police forces have developed guidelines on sharing information related to incidents, criminal investigations and missing persons in order not to interfere with ongoing investigations or damage the privacy of suspects or victims (Metropolitan Police, 2017: 3; ACPO, 2015: 5-6; PSNI, 2017: 4-5; Dutch police, 2018: 29-30; Dutch police, 2018a; Dutch police, 2018b; Police Scotland, 2018: 7). These structural barriers are managed with strategies of exploitation: creating rules and encouraging standardized practices.

Day-to-day management of social media accounts is left mainly at the discretion of individual users - indicating a strategy of exploration. Policies prescribe that regular updates and timely responses are required. The Dutch police forces are aware that the public expects to be able to reach them and get timely responses on each platform where police have a presence (Dutch police, 2018: 11). As a general guideline, posting with a minimum of twice a week, daily monitoring of the account and responding to citizen requests within 24 hours is suggested (Ibid.: 27).

\subsection{Overcoming cultural government barriers}

Policies describe how social media fit the police organization and how communication should fit police values such as 'integrity, fairness and respect' (Police Scotland, 2018: 6) or 'integrity, trustworthiness, courage and interconnectedness' (Dutch police, 2018: 29). As social media platforms come and go, the police need to be adaptable to be able to effectively communicate. Most police forces maintain various social media accounts for different purposes and publics. For example, the Dutch police distinguishes between corporate, geographical, personal and thematic accounts on Twitter, Facebook, YouTube, Instagram and Snapchat (Dutch police, 2018: 5). Police Scotland (2016) manages one corporate Twitter account, several geographical accounts and eight specialist accounts, including accounts of the police helicopter, road police, police horses and police dogs. Experimenting with a variety of accounts is an example of exploration.

The reputational risks as a result of heightened exposure and visibility receive much attention in the policies. The policies stress that social media accounts represent the police organization and can either enhance or damage police reputation (Dutch police, 2018: 29; Police Scotland, 2018: 10). Police forces seek to keep in control of online communication by specifying what types of content can and cannot be communicated. PSNI (2017: 10) published 'ten golden rules' of what and how to communicate. One of these rules specifies how political and religious posts are considered inappropriate. ACPO (2013: 5) prescribes when the police should not use social media, for instance off duty or when for any reason one's judgment may be impaired. Many policies also offer best practice cases to showcase desirable ways of communicating on social media (ACPO, 2011; Dutch police, 2018a).

When inappropriate content is posted that may damage police reputation by causing confusion or upset, policies state that police officers should notify the media department and/or senior management (Police Scotland, 2018). Increasingly, police forces structurally monitor social media communication, both by and about the police, to manage reputational risks (e.g. Police Scotland, 2018; PSNI, 2017, Dutch police, 2018). UK police forces have been clamping down on anonymous, unofficial use of social media by police officers and new officers on the force are asked to clean or delete their personal social media accounts (cf. Burnett et al., 2012; Goldsmith, 2015; Pedersen et al., 2014). Through these risk management practices, we recognize a strategy of exploitation instead of exploration.

\subsection{Overcoming structural citizen barriers}

The Dutch and UK police social media policies demonstrate an awareness of digital inequalities in society (Dutch police, 2018: 9; Metropolitan Police, 2017; Police Scotland, 2018; PSNI, 2017; ACPO, 2011; 2013: 4). The Metropolitan Police, for example, provide data on the share of citizens (not) having smartphones and access to broadband internet (Metropolitan Police, 2017: 11). Police officers are encouraged to use plain language and visual images as a universal language, to be accessible and to actively enlarge their follower base (Dutch police, 2018: 13; PSNI 2017: 7, 10; Police Scotland 2018: 6). Here, we recognize the exploration strategy.

Online anonymity and the informal and unstructured character of requests does not register as a concern in any of the social media policies. We assume that this citizen barrier is less experienced in the context of the UK and the Netherlands. Having a large and professional social media presence, these police forces gained experience in responding to the full breadth and volume of online requests.

\subsection{Overcoming cultural citizen barriers}

To avoid a mismatch of social media presence and communication with different types of audiences, Dutch and UK police forces explicitly choose to adopt a different communication strategy for each specific platform. Police Scotland (2018: 6) specifies that their media management ensures that their communications are 'audience-focused'. The Dutch Police (2018: 11) explicates that the style and phrasing of the content is attuned to the specific target group. At the same time, all police social media accounts are required to use the police corporate identity and layout and clear bio-information to be recognizable as official accounts. The Dutch social media policy, for example, encourages that the profile picture contains a picture in official uniform and that bios state that social media are not meant for emergency 
Table 4

Identified strategies to overcome barriers of adopting social media in policework

\begin{tabular}{|c|c|c|}
\hline & Barriers & Strategies \\
\hline \multirow[t]{3}{*}{$\begin{array}{l}\text { Structural government } \\
\text { barriers }\end{array}$} & $\begin{array}{l}\text { Limited resources (hardware, software and personnel, including lack of } \\
\text { managerial commitment) }\end{array}$ & $\begin{array}{l}\text { Managerial support, agreements on time, capacity and resources. } \\
\text { For example providing platforms to manage and monitor social } \\
\text { media }\end{array}$ \\
\hline & $\begin{array}{l}\text { No embedding of social media in existing organizational processes leading to } \\
\text { lack of training and knowledge exchange }\end{array}$ & $\begin{array}{l}\text { Explicating goals and responsibilities of social media use. } \\
\text { Guidelines for starting accounts and managing critical incidents or } \\
\text { mistakes }\end{array}$ \\
\hline & $\begin{array}{l}\text { No management of social media communication: lack of clear protocols and } \\
\text { guidance }\end{array}$ & $\begin{array}{l}\text { Guidelines managing accounts: what information to post and } \\
\text { account activity. Leaving room for individual discretion }\end{array}$ \\
\hline \multirow[t]{3}{*}{$\begin{array}{l}\text { Cultural government } \\
\text { barriers }\end{array}$} & $\begin{array}{l}\text { Lack of fit of social media culture with police culture of communication } \\
\text { (horizontal, informal and many-to-many vs. hierarchical, formal and one-to- } \\
\text { many) }\end{array}$ & $\begin{array}{l}\text { Explicating that communication should fit police values, identify } \\
\text { risks to the police function, develop guidelines for sharing } \\
\text { sensitive information }\end{array}$ \\
\hline & $\begin{array}{l}\text { Ineffective communication on social media due to challenges related to the } \\
\text { adaptability to the (changing) social media landscape, fitting communication } \\
\text { to each platform's target group and features }\end{array}$ & Being active on multiple platforms, variety of account types \\
\hline & $\begin{array}{l}\text { Risks to police reputation and legitimacy due to heightened visibility of } \\
\text { policework on social media }\end{array}$ & $\begin{array}{l}\text { Guidelines for types of content that can be shared leaving room } \\
\text { for individuals discretion, but monitoring and procedures in case } \\
\text { of mistakes }\end{array}$ \\
\hline \multirow[t]{2}{*}{ Structural citizen barriers } & $\begin{array}{l}\text { Digital inequalities and unequal reach of communication because certain } \\
\text { groups are less acquainted with social media }\end{array}$ & Encouraging accessible communication for a variety of followers \\
\hline & $\begin{array}{l}\text { Relatively anonymous, unstructured and informal social media requests may } \\
\text { be misinterpreted }\end{array}$ & a \\
\hline \multirow[t]{3}{*}{ Cultural citizen barriers } & $\begin{array}{l}\text { Mismatch of social media in style of communication; citizens mistaking bogus } \\
\text { police accounts for real }\end{array}$ & $\begin{array}{l}\text { Explicating choice of platforms, 'audience-focused' } \\
\text { communication and corporate identity that is recognizable as } \\
\text { official }\end{array}$ \\
\hline & $\begin{array}{l}\text { Limited trust of citizens in the police causing limited willingness to engage } \\
\text { since social media presence may be regarded as surveillance }\end{array}$ & a \\
\hline & $\begin{array}{l}\text { Perverse effects of enhanced fear of crime due to more frequent } \\
\text { communication on crime }\end{array}$ & a \\
\hline
\end{tabular}

a These barriers were not addressed in UK and Dutch police's social media policies. Please see the discussion on p. 19-20.

contact.

Willingness of citizens to engage with police on social media and enhanced fear of crime is not addressed in the UK and Dutch policies. This is likely due to a tradition of community policing in both countries. As day-to-day interaction with the police is also common offline, online police presence is not so much perceived as a form of surveillance.

\subsection{Analysis of policies for tackling barriers to social media adoption}

Various barriers are addressed through social media policies of Dutch and UK police forces (see Table 4). Social media policies of these advanced cases mostly focus on structural and cultural barriers on the side of government. Attention to structural and cultural barriers on the part of citizens is limited - this is likely due to the local contexts where these barriers are less present.

The police departments use mixed approaches of exploration and exploitation: exploitation strategies are used to address structural barriers and exploration strategies are employed to address cultural barriers. Policies indicate standardization and central procedures when it comes to resources and management of social media accounts (PSNI, 2017, Dutch police, 2018). Also the creation of accounts and management of account security is addressed with a strategy of exploitation. Within these boundaries, police officers are free to use social media in ways that they deem appropriate. For example, the Dutch social media policy (2018: 12) explicitly mentions experimentation and 'learning by doing'. Explorative policies encourage individual users to adjust the message to various platforms and publics while avoiding posting content which is partisan or controversial. Only when content causes confusion or upset, exploitation strategies are deployed which include procedures of notifying upper management. Barriers on the side of citizens are also managed with strategies of exploration. Guidelines are formulated in an effort to make police communication both relatable and accessible.

\section{Conclusions}

Social media practices of police forces vary greatly (Brainard and Edlins, 2015; Crump, 2011). Police are dealing with a variety of barriers to social media adoption which explain differentiated practices. Structural barriers in government organizations have received a lot of attention (Mergel, 2012; Picazo-Vela et al., 2016). However, cultural barriers on the side of government are also experienced prominently and in a variety of ways. These include a mismatch between police culture and social media culture, adaptability of style of communication to different platforms and having to relinquish full control over the police's public image due to the heightened visibility of policework. In addition, barriers on the side of citizens such as digital inequalities, the anonymity of social media communication, lack of trust and perverse effects such as enhanced fear of crime also prevent social media adoption by police.

In line with the work of March (1991), we find that the Dutch and UK police combine strategies of exploration and exploitation in the process of social media adoption. The social media policies do not address all the identified barriers in this study. The focus is largely on the structural and cultural barriers on the side of the police. The social media policies do not consider the barriers on the side of citizens to the same extent, probably due to the local contexts where these barriers are less present. To overcome structural barriers on the side of police, policies use a strategy of exploitation via standardization, regulation and division of responsibilities. To overcome the cultural barriers on the side of police, policies leave space for adaptability, variation of use and discretion of individual police officers - indicating a strategy of exploration. This enables variation and experimentation within the police organization and in adaptation to the changing context of social media (cf. Fernandez et al., 2017).

This combination of innovation approaches runs counter to the expectations of the staged models of innovation. In these models, exploitation would be considered as the final stage, or would be employed in the advanced phases of adoption. The two advanced cases of the UK and Dutch police indicate that the two strategies exist in parallel and 
offer an effective way to address both structural and cultural barriers to innovation adoption. This highlights an iterative process of innovation adoption and aligns with the idea of the 'perpetual beta', a design principle in software development. This occurs when the system is kept in a development stage for an extended or indefinite period of time. Instead of delivering a finished service, users are treated as co-developers from which the organization learns and is able to adjust.

Recognizing these tensions, this article argues that the way that barriers to social media adoption are managed in policing, provides valuable lessons on how they can be managed in other public organizations. Hence, this research contributes to more general theory on the adoption of social media and e-governance innovation. Also in other types of organizations, social media are sometimes only used to a limited extent: for example only for broadcasting and not for dialogue (cf. Oliveira and Welch, 2013; Zavattaro and Brainard, 2019). Our research into social media adoption by the police suggests that in these organizations as well, cultural rather than structural barriers could explain limited practices.

Instead of better embedding social media practices in rules and procedures, an exploration strategy to innovation presents a better way to manage social media adoption. This requires an environment that permits and supports social media innovation. Choosing only an exploitation strategy to manage social media adoption can have a limiting effect on variability and adaptability to the external context of the organization. Therefore, maintaining an exploration strategy, even in advanced stages of innovation adoption - the approach of the 'perpetual beta' - can achieve better effects in overcoming barriers to social media adoption.

However, police organizations offer an exceptional case to study barriers to e-governance innovation in public organizations (Flyvbjerg, 2006; Yin, 2017). Their authoritative position conflicts with the horizontally networked structure and informal exchanges of social media (Crump, 2011; Meijer and Thaens, 2013). In other public organizations, cultural barriers may therefore be less prominent.

The current study has several limitations: First, this study analyzed policies as they exist on paper. While the UK and the Netherlands are frontrunner cases, the policies themselves provide little insight in the effectiveness of specific social media practices. Secondly, based on two cases in a Western European context, we cannot draw conclusions on whether a combination of exploration and exploitation would also be effective in other contexts.

Based on these limitations, we advise future research to focus on effects of these policies in practice, for example by way of interviews with social media users and managers within the police. This will gain better insight into how effective the policies were in enhancing communication and engagement with the public. Also, we suggest to comparative research with police organizations in other contexts (for example police forces that did not adopt a community policing philosophy). This will be helpful to learn whether similar barriers to social media adoption exist and whether a combination of exploration and exploitation is always the most effective.

\section{References $^{2}$}

Bertot, J. C., Jaeger, P. T., \& Hansen, D. (2012). The impact of polices on government social media usage: Issues, challenges, and recommendations. Government Information Quarterly, 29(1), 30-40.

Beshears, M. L. (2017). Effectiveness of police social media use. American Journal of Criminal Justice, 42(3) 489-501*.

Bloch, C., \& Bugge, M. M. (2013). Public sector innovation. From theory to measurement. Structural Change and Economic Dynamics, 27, 133-145.

Bohanon, A. L. (2016). Tweeting the police: Balancing free speech and decency on government-sponsored social media pages. Minnesota Law Review, 101(1) 341-382*.

Brainard, L. (2016). An internet utopia? Government use of web technologies to engage citizens in the US. International Journal of Organization Theory and Behavior, 19(4),

\footnotetext{
${ }^{2}$ Note: references with an * were included in the systematic literature review.
}

$459-478$.

Brainard, L., \& Edlins, M. (2015). Top 10 U.S. municipal police departments and their social media usage. The American Review of Public Administration, 45(6) 728-745*.

Bullock, K. (2018a). (Re)presenting 'order' online: The construction of police presentational strategies on social media. Policing and Society, 28(3) 345-359*.

Bullock, K. (2018b). The police use of social media: Transformation or normalisation? Social Policy and Society, 17(2) 245-258*.

Burnett, S., Pedersen, S., Smith, R., \& O'Neill, A. (2012). Venting, joining and educating: Motivations for knowledge sharing in the UK police blogosphere. Business Information Review, 29(1) 57-63*.

Campbell, D. A., Lambright, K. T., \& Wells, C. J. (2014). Looking for friends, fans, and followers? Social media use in public and nonprofit human services. Public Administration Review, 74(5), 655-663.

Coursey, D., \& Norris, D. F. (2008). Models of e-government: Are they correct? An empirical assessment. Public Administration Review, 68(3), 523-536.

Criado, J. I., Sandoval-Almazan, R., \& Gil-Garcia, J. R. (2013). Government innovation through social media. Government Information Quarterly, 30(4), 319-326.

Crump, J. (2011). What are the police doing on Twitter? Social media, the police and the public. Policy \& Internet, 3(4) 1-27*.

Dai, M., He, W., Tian, X., Giraldi, A., \& Gu, F. (2017). Working with communities on social media: Varieties in the use of Facebook and Twitter by local police. Online Information Review, 41(6) 782-796*.

Davis, E. F., Alves, A. A., \& Sklansky, D. A. (2015). Social media and police leadership: Lessons from Boston. Modern perspectives on policing: Selected papers 71-92*

De Graaf, G., \& Meijer, A. J. (2019). Social media and value conflicts: An explorative study of the Dutch police. Public Administration Review, 79(1), 82-92 Online first*

Dekker, R., \& Bekkers, V. (2015). The contingency of governments' responsiveness to the virtual public sphere: A systematic literature review and meta-synthesis. Government Information Quarterly, 32(4), 496-505.

Dodgson, M., Gann, D. M., \& Salter, A. (2008). The management of technological innovation: Strategy and practice. Oxford: Oxford University Press.

Earl, J., McKee Hurwitz, H., Mejia Mesinas, A., Tolan, M., \& Arlotti, A. (2013). This protest will be tweeted: Twitter and protest policing during the Pittsburgh G20. Information, Communication \& Society, 16(4) 459-478*.

Edlins, M., \& Brainard, L. A. (2016). Pursuing the promises of social media? Changes in adoption and usage of social media by the top 10 U.S. police departments. Information Polity, 21(2) 171-188*

Eynon, R., \& Dutton, W. H. (2007). Barriers to networked governments: Evidence from Europe. Prometheus, 25(3), 225-242.

Eynon, R., \& Margetts, H. (2007). Organisational solutions for overcoming barriers to egovernment. European Journal of ePractice, 1, 1-13.

Fernandez, M., Dickinson, T., \& Harith, A. (2017). An analysis of UK policing engagement via social media. In G. Ciampaglia, A. Mashhadi, \& T. Yasseri (Eds.). Social informatics. SocInfo 2017 (pp. 289-304). Springer Lecture Notes in Computer Science.

Fink, A. (2010). Conducting research literature reviews. From the Internet to Paper (3rd ed.). California: Sage Publications (Chapter 1).

Flyvbjerg, B. (2006). Five misunderstandings about case-study research. Qualitative Inquiry, 12(2), 219-245.

Fowler, B. M. (2017). Stealing thunder and filling the silence: Twitter as a primary channel of police crisis communication. Public Relations Review, 43(4) 718-728*

Goldsmith, A. (2015). Disgracebook policing: Social media and the rise of police indiscretion. Policing and Society, 25(3) 249-267*.

Greer, C., \& McLaughlin, E. (2010). We predict a riot?: Public order policing, new media environments and the rise of the citizen journalist. British Journal of Criminology, 50(6) 1041-1059*.

Grimmelikhuijsen, S. G., \& Meijer, A. J. (2015). Does Twitter increase perceived police legitimacy? Public Administration Review, 75(4) 598-607*.

Gupta, A. K., Smith, K. G., \& Shalley, C. E. (2006). The interplay between exploration and exploitation. Academy of Management Journal, 49(4), 693-706.

Heverin, T., \& Zach, L. (2010). Twitter for city police department information sharing Proceedings of the ASIST Annual Meeting. 47*.

Ho, K. K. W., Yu, C. C., \& Lai, M. C. L. (2014). Engaging and developing the community through social media: A pragmatic analysis in policing context in Hong Kong. Government e-strategic planning and management: Practices, patterns and roadmaps 263 $285^{*}$.

Hu, X., Rodgers, K., \& Lovrich, N. P. (2018). "We are more than crime fighters": Social media images of police departments. Police Quarterly*, 21(4), 544-572.

Huang, Y., Wu, Q., Huang, X., \& Bort, J. (2017). A multiplatform investigation of law enforcement agencies on social media. Information Polity, 22(2-3) 179-196*.

Jones, M. A., \& De Guzman, M. C. (2010). E-policing: The value of police websites for citizen empowered participation. E-government website development: Future trends and strategic models 211-227*.

Jones, M. A., De Guzman, M. C., \& Kumar, K. S. (2014). Using web 2.0 as a community policing strategy: An examination of the united states municipal police departments. Cyber behavior: Concepts, methodologies, tools, and applications 866-879*.

Liberati, A., Altman, D. G., Tetzlaff, J., Murlow, C., Gotzsche, P. C., Loannidis, J. T. A., Moher, D. (2009). The PRISMA statement for reporting systematic reviews and metaanalayses of studies that evaluate health care interventions: Explanation and elaboration. PLoS Medicine, 6(7).

Lieberman, J. D., Koetzle, D., \& Sakiyama, M. (2013). Police departments' use of Facebook: Patterns and policy issues. Police Quarterly, 16(4) 438-462*.

Madichie, N. O., \& Hinson, R. (2014). A critical analysis of the "dialogic communications" potential of Sub-Saharan African police service websites. Public Relations Review, 40(2) $338-350 *$.

Manzoor, A. (2015). Use of social media for policing. Handbook of research on cultural and economic impacts of the information society $297-326 *$ 
March, J. G. (1991). Exploration and exploitation in organizational learning. Organization Science, 2(1), 71-87.

Margetts, H., \& Dunleavy, P. (2002). Better public services through e-government: academic article in support of better public services through e-government. National Audit Office report, HC 704-III session 2001-2London, UK: The Stationery Office.

Medi@4Sec (2016). Worldwide mapping of best practices and lessons learnt. EU Horizon 2020 project deliverable. Retrieved August 10, 2018 from: http://media4sec.eu/ downloads/d1-2.pdf.

Meijer, A. J. (2015). E-governance innovation: Barriers and strategies. Government Information Quarterly, 32(2), 198-206.

Meijer, A. J., \& Thaens, M. (2013). Social media strategies: Understanding the differences between North American police departments. Government Information Quarterly, 30(4) $343-350 *$.

Meijer, A. J., \& Torenvlied, R. (2016). Social media and the new organization of government communications: An empirical analysis of Twitter usage by the Dutch police. The American Review of Public Administration, 46(2) 143-161*.

Mergel, I. (2012). The social media innovation challenge in the public sector. Information Polity, 17(3, 4), 281-292.

Mergel, I. (2013). Social media adoption and resulting tactics in the US federal govern ment. Government Information Quarterly, 30(2), 123-130.

Mergel, I., \& Bretschneider, S. I. (2013). A three-stage adoption process for social media use in government. Public Administration Review, 73(3), 390-400.

Moher, D., Liberati, A., Tetzlaff, J., Altman, D. G., \& PRISMA Group (2009). Preferred reporting items for systematic reviews and meta-analyses: the PRISMA statement. Annals of Internal Medicine, 151(4), 264-269.

Moon, M. J. (2002). The evolution of e-government among municipalities: Rhetoric or reality. Public Administration Review, 62(4), 424-433.

O'Connor, C. D. (2017). The police on Twitter: Image management, community building, and implications for policing in Canada. Policing and Society, 27(8) 899-912*.

Oliveira, G. H. M., \& Welch, E. W. (2013). Social media use in local government: Linkage of technology, task, and organizational context. Government Information Quarterly, 30(4), 397-405.

Omanga, D. (2015). 'Chieftaincy' in the social media space: Community policing in a Twitter convened baraza. Stability, $4(1)^{*}$.

Osborne, S. P., \& Brown, K. (2005). Managing change and innovation in public service organizations. Abingdon: Routledge.

Pedersen, S., Burnett, S., Smith, R., \& Grinnall, A. (2014). The impact of the cessation of blogs within the UK police blogosphere. New Technology, Work and Employment, 29(2) 160-176*.

Picazo-Vela, S., Gutiérrez-Martínez, I., \& Luna-Reyes, L. F. (2012). Understanding risks, benefits, and strategic alternatives of social media applications in the public sector. Government Information Quarterly, 29(4), 504-511.
Picazo-Vela, S., Fernandez-Haddad, M., \& Luna-Reyes, L. F. (2016). Opening the black box: Developing strategies to use social media in government. Government Information Quarterly, 33(4), 693-704.

Procter, R., Crump, J., Karstedt, S., Voss, A., \& Cantijoch, M. (2013). Reading the riots: What were the police doing on Twitter? Policing and Society, 23(4) 413-436*.

Rogers, E. M. (2003). Diffusion of innovations (5th ed.). New York: The Free Press.

Rosenbaum, D. P., Graziano, L. M., Stephens, C. D., \& Schuck, A. M. (2011). Understanding community policing and legitimacy-seeking behavior in virtual reality: A national study of municipal police websites. Police Quarterly, 14(1) 25-47*.

Ruddell, R., \& Jones, N. (2013). Social media and policing: Matching the message to the audience. Safer Communities, 12(2) 64-70*.

Schneider, C. J. (2014). Police 'image work' in an era of social media: YouTube and the 2007 Montebello summit protest. Social media, politics and the state: Protests, revolutions, riots, crime and policing in the age of Facebook, Twitter and YouTube 227-246*.

Schneider, C. J. (2016). Police presentational strategies on Twitter in Canada. Policing and Society, 26(2) 129-147*.

Sillince, J. A. A., \& Brown, A. D. (2009). Multiple organizational identities and legitimacy: The rhetoric of police websites. Human Relations, 62(12) 1829-1856*.

Toch, H. (2012). Cop watch: Spectators, social media, and police reform. American Psychological Association*.

Trottier, D., \& Fuchs, C. (2014). Social media, politics and the state: Protests, revolutions, riots, crime and policing in the age of Facebook, Twitter and YouTube. Abingdon: Routledge*.

Van De Velde, B., Meijer, A., \& Homburg, V. (2015). Police message diffusion on Twitter: Analysing the reach of social media communications. Behaviour \& Information Technology, 34(1) 4-16*.

Walsh, D., \& Downe, S. (2005). Meta-synthesis method for qualitative research: a literature review. Methodological Issues in Nursing Research, 50, 204-211.

Williams, C. B., Fedorowicz, J., Kavanaugh, A., Mentzer, K., Thatcher, J. B., \& Xu, J. (2018). Leveraging social media to achieve a community policing agenda. Government Information Quarterly, 35(2) 210-222*.

Yavuz, N., \& Welch, E. W. (2014). Factors affecting openness of local government websites: Examining the differences across planning, finance and police departments. Government Information Quarterly, 31(4) 574-583*.

Yin, R. K. (2017). Case study research and applications: Design and methods. Sage Publications.

Zavattaro, S. M., \& Brainard, L. A. (2019). Social media as micro-encounters: Millennial preferences as moderators of digital public value creation. International Journal of Public Sector Management, 32(5), 562-580 Earlycite.

Zimmer, L. (2006). Qualitative meta-synthesis: A question of dialoguing with texts. Jan. Leading Global Nursing Research, 53(3), 311-318. 